\title{
Improved light trapping in microcrystalline silicon solar cells by plasmonic back reflector with broad angular scattering and low parasitic absorption
}

\author{
Hairen Tan, ${ }^{1, a)}$ Laura Sivec, ${ }^{2}$ Baojie Yan, ${ }^{2}$ Rudi Santbergen, ${ }^{1}$ Miro Zeman, ${ }^{1}$ \\ and Arno H. M. Smets ${ }^{1, a)}$ \\ ${ }^{1}$ Photovoltaic Materials and Devices Laboratory, Delft University of Technology, Mekelweg 4, Delft 2628CD, \\ The Netherlands \\ ${ }^{2}$ United Solar Ovonic LLC, Troy, Michigan 48084, USA
}

(Received 16 February 2013; accepted 4 April 2013; published online 18 April 2013)

\begin{abstract}
We show experimentally that the photocurrent of thin-film hydrogenated microcrystalline silicon ( $\mu \mathrm{c}-\mathrm{Si}: \mathrm{H})$ solar cells can be enhanced by $4.5 \mathrm{~mA} / \mathrm{cm}^{2}$ with a plasmonic back reflector (BR). The light trapping performance is improved using plasmonic BR with broader angular scattering and lower parasitic absorption loss through tuning the size of silver nanoparticles. The $\mu \mathrm{c}-\mathrm{Si}: \mathrm{H}$ solar cells deposited on the improved plasmonic BR demonstrate a high photocurrent of $26.3 \mathrm{~mA} / \mathrm{cm}^{2}$ which is comparable to the state-of-the-art textured $\mathrm{Ag} / \mathrm{ZnO} \mathrm{BR}$. The commonly observed deterioration of fill factor is avoided by using $\mu \mathrm{c}-\mathrm{SiO}_{x}: \mathrm{H}$ as the n-layer for solar cells deposited on plasmonic BR. (C) 2013 AIP Publishing LLC [http://dx.doi.org/10.1063/1.4802451]
\end{abstract}

Effective light trapping in thin-film microcrystalline silicon $(\mu \mathrm{c}-\mathrm{Si}: \mathrm{H})$ solar cells is crucial to obtain high photocurrent and to reduce the absorber layer thickness, which in state-of-the-art devices is commonly realized using randomly textured substrates. ${ }^{1-5}$ Recently, plasmonic metal nanoparticles have attracted extensive interest to further improve the light trapping in solar cells since metal nanoparticles can efficiently scatter the incident light into absorber layer. ${ }^{6-14}$ Enhanced photocurrent in $\mu \mathrm{c}-\mathrm{Si}: \mathrm{H}$ solar cells has been demonstrated using periodic metallic gratings and random metal nanoparticles as rear reflectors, which here we refer to as plasmonic back reflector (BR). By depositing $\mu \mathrm{c}-\mathrm{Si}: \mathrm{H}$ solar cells on periodic metallic reflector, Paetzold et al. demonstrated that the photocurrent can be increased to $21.0 \mathrm{~mA} /$ $\mathrm{cm}^{2}$, compared to $17.7 \mathrm{~cm} / \mathrm{cm}^{2}$ for a planar cell. ${ }^{12}$ Bhattacharya et al. reported that the photocurrent increased to $21.5 \mathrm{~mA} / \mathrm{cm}^{2}$ by a photonic-plasmonic BR. ${ }^{13}$ Chantana et al. demonstrated that the photocurrent can be increased to $22.3 \mathrm{~mA} / \mathrm{cm}^{2}$ by the plasmonic BR with a random array of silver nanoparticles (Ag NPs). ${ }^{14}$

Although plasmon-enhanced light trapping has been demonstrated relative to flat reference devices, so far the plasmonic light trapping capability in $\mu \mathrm{c}-\mathrm{Si}: \mathrm{H}$ solar cells remains considerably below the levels attained by state-ofthe-art textured substrates. ${ }^{11-14}$ One of the main reasons is the considerable parasitic absorption in the plasmonic BR. Scattering mainly into low angles (close to the surface normal) is another possible factor limiting the light trapping performance. The effects of plasmonic losses and the angular resolved scattering of the plasmonic BR on the light trapping performance have not received much attention to date. In this work, we investigate the correlation between the size of Ag NPs and the parasitic absorption and angular scattering of the plasmonic BR. We show that the light trapping is improved by the plasmonic BR with broader angular scattering and lower parasitic absorption. Accordingly, the

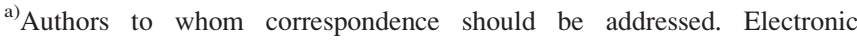
addresses: h.tan@tudelft.nl and a.h.m.smets@tudelft.nl
}

improved plasmonic BR results in a high photocurrent of $26.3 \mathrm{~mA} / \mathrm{cm}^{2}$ in a $2 \mu \mathrm{m}$-thick $\mu \mathrm{c}$-Si:H solar cell, which is comparable to the state-of-the-art textured $\mathrm{Ag} / \mathrm{ZnO} \mathrm{BR}$.

The structure of the plasmonic BR is shown in Fig. 1(a). It consists of glass/flat Ag $(100 \mathrm{~nm}) / \mathrm{AZO}(60 \mathrm{~nm}) / \mathrm{Ag} \mathrm{NPs} /$ AZO $(30 \mathrm{~nm})$ layers, where AZO stands for Al-doped $\mathrm{ZnO}$ (ZnO:Al). The Ag NPs were formed by a self-assembly method, and the size of Ag NPs can be tuned by the initial thickness of as-deposited Ag film and annealing temperature. Experimental details can be found in our previous works. ${ }^{9,15}$ Reflection measurements were performed with a PerkinElmer Lambda 950 spectrophotometer. Angular resolved scattering was measured with an Angular Resolved Analyzer integrated in the spectrophotometer as discussed in Ref. 16. The n-i-p $\mu$ c-Si:H solar cells with $\sim 2 \mu$ m-thick intrinsic absorber layers were fabricated by plasma enhanced (a)

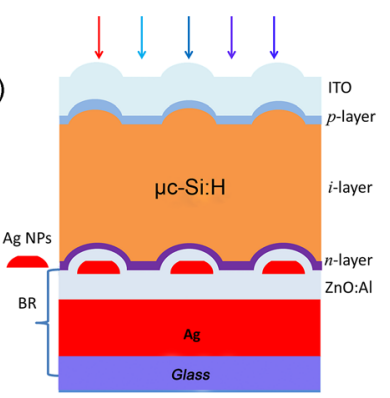

(c)

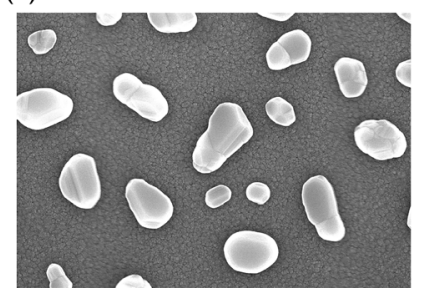

(b)

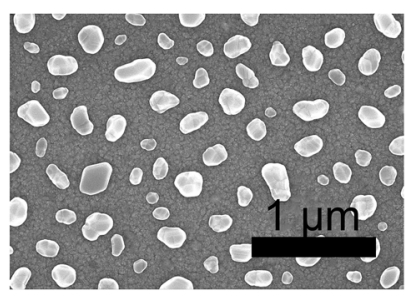

(d)

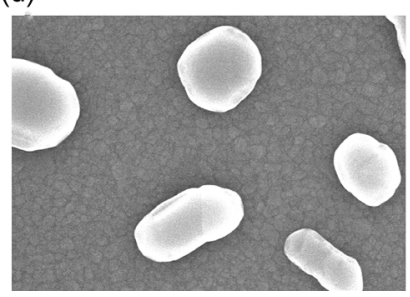

FIG. 1. (a) Schematic device structure of the n-i-p $\mu$ c-Si:H solar cells deposited on the plasmonic BRs. SEM images of the Ag NPs with average lateral diameters of (b) 150 , (c) 350, and (d) $600 \mathrm{~nm}$ in the plasmonic BRs. Here, the AZO layers on top of Ag NPs were not deposited for the SEM measurements, and images (b)-(d) have the same scale bar. 
chemical vapor deposition. The solar cells were completed by sputtering an $80 \mathrm{~nm}$-thick ITO layer and Ag grids as top electrode. The $V_{o c}$ and $F F$ were determined from $J-V$ measurements under an AM1.5G $\left(100 \mathrm{~mW} / \mathrm{cm}^{2}\right)$ solar simulator at $25^{\circ} \mathrm{C}$. To better evaluate the light trapping, the external quantum efficiency (EQE) measurements were carried out at a negative bias. The photocurrent was calculated from EQE curves by convolution with the photon flux of AM1.5G solar spectrum between 300 and $1100 \mathrm{~nm}$.

Plasmonic Ag NPs can scatter and absorb light through the excitation of localized surface plasmons, which depends on the size and shape of the NPs. ${ }^{7}, 17$ According to Mie-theory, the multipolar resonances appear at longer wavelengths as the diameter of spherical Ag NPs increases, indicating broadband light scattering can be achieved by tuning the size of NPs. Meanwhile, the parasitic absorption by $\mathrm{Ag}$ NPs decreases as the size increases. The Ag NPs with diameter larger than $100 \mathrm{~nm}$ have broadband scattering over the spectral range (up to $1100 \mathrm{~nm}$ ) relevant for $\mu \mathrm{c}-\mathrm{Si}: \mathrm{H}$ solar cells. ${ }^{7}$ Here, we choose three plasmonic BRs containing Ag NPs with average lateral diameters of 150,350 , and $600 \mathrm{~nm}$ as shown in Figs. 1(b)-1(d), respectively. These Ag NPs with different sizes have similar surface coverage of $\sim 20 \%$ and circularity of $\sim 86 \%$. A lateral diameter of $600 \mathrm{~nm}$ is significantly larger than the size typically used for plasmonic solar cells in other works. The larger Ag NPs are expected to have lower parasitic absorption as well as efficient light scattering over a broad wavelength range.

From Fig. 2(a), it can be seen that the reflectance of the plasmonic BRs increases by increasing the size of Ag NPs, indicating that the parasitic absorption loss reduces with the increase of size. When the size increases from 150 to $350 \mathrm{~nm}$, the average reflectance in the range of $600-1100 \mathrm{~nm}$ significantly improves from $57 \%$ to $84 \%$. Further increase of the size to $600 \mathrm{~nm}$ improves the average reflectance to $88 \%$. However, the reflectance of the plasmonic BR is still lower

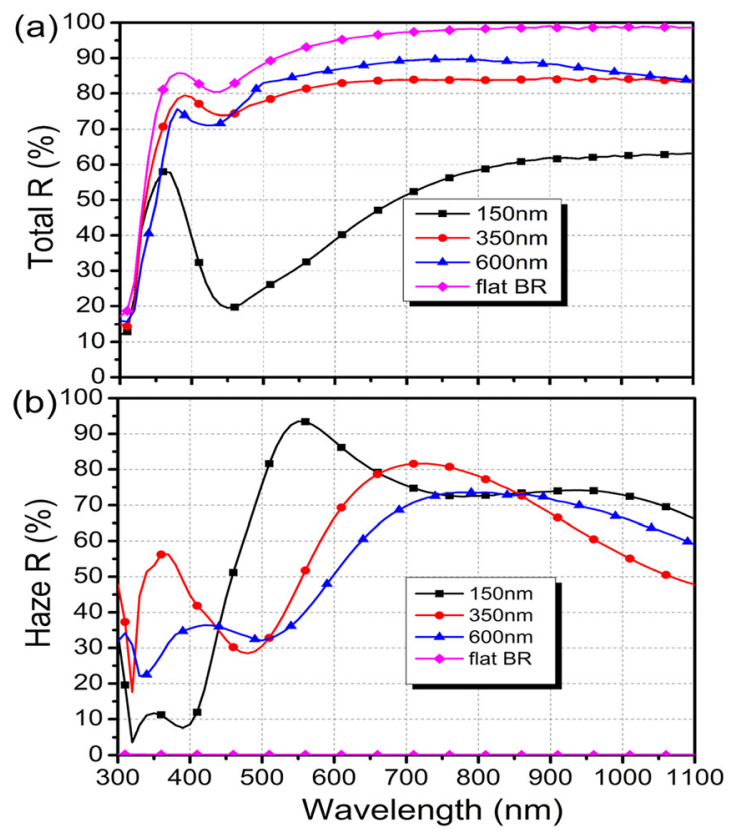

FIG. 2. Total reflection (a) and haze in reflection (b) of the flat BR and the plasmonic BRs with Ag NPs size of 150,350 , and $600 \mathrm{~nm}$. than the flat BR whose reflectance is higher than $95 \%$ at wavelengths from 600 to $1100 \mathrm{~nm}$. Nevertheless, it should be noted that the reflectance of the plasmonic BR in solar cells will be higher than the measured reflectance in air since the light trapped within the $\mathrm{ZnO}$ will enter into the silicon when solar cells are made on the BRs. Measurements of haze in reflection (shown in Fig. 2(b)) reveal that the size has great influence on the scattering properties of the plasmonic BRs. The increase of size shifts the plasmon-resonance peaks to longer wavelengths. In the crucial wavelength range for light trapping in $\mu \mathrm{c}-\mathrm{Si}: \mathrm{H}$ solar cells $(700-1000 \mathrm{~nm})$, the three plasmonic BRs have reasonably high haze values. A higher surface coverage is needed to achieve $100 \%$ haze in reflection. However, it is difficult to control the surface coverage for self-assembled Ag NPs.

Although the haze parameter is commonly used to evaluate the light trapping potential, recent studies also emphasize the importance of angular intensity distribution (AID) of scattered light to achieve efficient light trapping. ${ }^{16,18}$ Light scattered into large angles, i.e., above the critical angle, is preferred since this light can be trapped inside the absorber layer by total internal reflection or by coupling into guided modes. The maximum absorption enhancement of $4 n^{2}(n$ is the refractive index of the absorber layer) for random textures is derived under the assumption of an ideal Lambertian scattering with an AID following a cosine distribution. Figure 3 shows the AID of the reflected light from the plasmonic BRs at the wavelengths of 700 and $800 \mathrm{~nm}$ measured in air. For comparison, the AID of a Lambertian reflector is also shown. As the size of Ag NPs increases from 150 to $600 \mathrm{~nm}$, incident light is scattered into larger angles more efficiently. The preferential scattering into larger angles by larger Ag NPs might be due to the excitation of additional higher-order localized surface plasmon modes and resonant surface plasmon polaritons modes, which scatter light into large angles more efficiently than the dipole modes (dominant in small metal nanoparticles). ${ }^{19,20}$ Overall, the broader angular scattering of plasmonic BR with larger Ag NPs is useful to increase the optical path length within the absorber layer and to enhance the total internal reflection at the interface between the $\mu \mathrm{c}-\mathrm{Si}: \mathrm{H}$ film and the ITO top electrode. For the plasmonic BR with Ag NPs size of $600 \mathrm{~nm}$, the AID is close to the Lambertian distribution. Remarkably, it even exceeds the Lambertian distribution between $25^{\circ}$ and $55^{\circ}$ around the resonance wavelength of $800 \mathrm{~nm}$.

To investigate the light trapping performance of the three plasmonic BRs, the $\mathrm{n}-\mathrm{i}-\mathrm{p}$ structured $\mu \mathrm{c}-\mathrm{Si}: \mathrm{H}$ solar cells were processed at $T U$ Delft on the BRs in the same deposition run. Figure 4(a) shows the EQE curves and the total device absorption (1-R) of corresponding solar cells. The positions of the maximal EQE are not the same due to small differences in the ITO thickness. Over the wavelength range between 600 and $1100 \mathrm{~nm}$, the EQE increases as the Ag NPs size increases from 150 to $600 \mathrm{~nm}$, indicating improved light trapping for the plasmonic BR with larger Ag NPs. The improvement of EQE can be attributed to two aspects. First, the larger Ag NPs have lower parasitic absorption, leading to less optical losses for the solar cells. The total device absorption in the three solar cells is almost the same, also indicating lower parasitic absorption losses for larger Ag NPs. Second, 

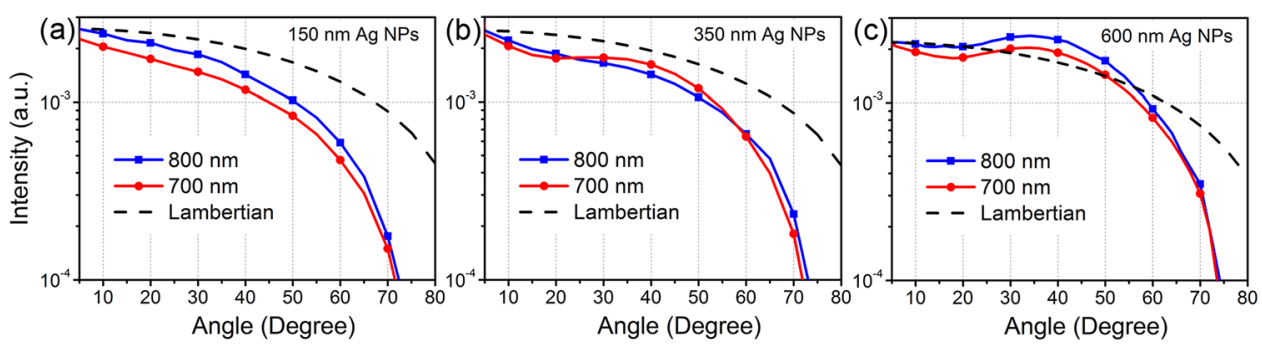

FIG. 3. The AID of the plasmonic BRs with Ag NPs size of (a) 150, (b) 350, and (c) $600 \mathrm{~nm}$ measured at wavelengths of 700 and $800 \mathrm{~nm}$ in air. The AID of a Lambertian reflector normalized to the highest intensity at the angle of $5^{\circ}$ is also shown for comparison. light is preferentially scattered into larger angle for larger Ag NPs, which more efficiently enhances the optical path length in the absorber layer. Especially for light scattered beyond the critical angle, it will be trapped in the absorber layer by total internal reflection.

To demonstrate the plasmon enhanced light trapping, $\mu \mathrm{c}-\mathrm{Si}: \mathrm{H}$ solar cells were deposited on the flat BR and the plasmonic BR with Ag NPs size of $600 \mathrm{~nm}$ using improved deposition recipe, where high-transparency microcrystalline silicon oxide $\left(\mu \mathrm{c}-\mathrm{SiO}_{x}: \mathrm{H}\right)$ were used as doped layers. Figure 4(b) shows the EQE curves of corresponding devices. At short wavelengths $(300-550 \mathrm{~nm})$ where light trapping does not play a role, the EQE of the two solar cells is the same. For wavelengths above $550 \mathrm{~nm}$, the EQE of the solar cell deposited on plasmonic BR is significantly enhanced in comparison to the planar cell. The improved EQE can be attributed to the strong scattering of light by the Ag NPs, which increases the optical path length in the photoactive layer compared to the flat BR. The corresponding photocurrent increases considerably from 21.0 to $25.5 \mathrm{~mA} / \mathrm{cm}^{2}$, resulting in a significant increase of the power conversion efficiency $(\eta)$ from $6.3 \%$ to $7.8 \%$.

To evaluate the light trapping capability of the plasmonic BR, it should be compared to the state-of-the-art textured $\mathrm{Ag} / \mathrm{ZnO} \mathrm{BR}$ which is well-known to have high-
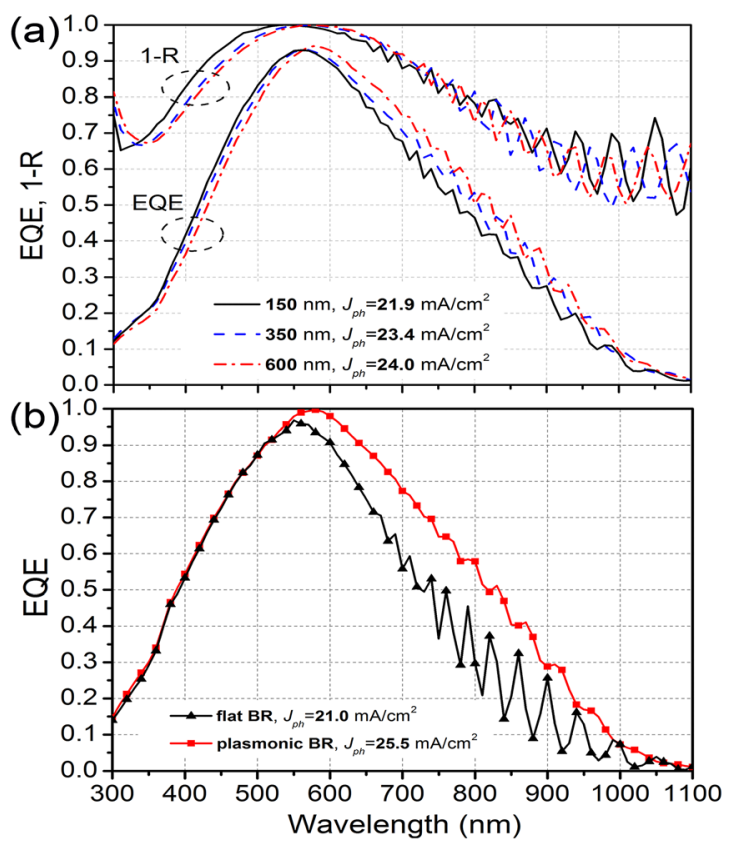

FIG. 4. (a) EQE and 1-R curves of solar cells deposited on the plasmonic BRs with Ag NPs size of 150,350 , and $600 \mathrm{~nm}$. (b) EQE of solar cells deposited on the flat BR and on the plasmonic BR with Ag NPs size of $600 \mathrm{~nm}$. performance light trapping in $\mu \mathrm{c}-\mathrm{Si}: \mathrm{H}$ solar cells. For this purpose, the $\mu \mathrm{c}-\mathrm{Si}: \mathrm{H}$ solar cells were deposited at United Solar on the plasmonic BR with Ag NPs size of $600 \mathrm{~nm}$ and on the state-of-the-art textured $\mathrm{Ag} / \mathrm{ZnO} \mathrm{BR}$. The textured $\mathrm{BR}$ consists of textured $\mathrm{Ag}$ layer and a thin $\mathrm{ZnO}$ (110-140 nm) layer, which is optimized for both good light trapping and for the growth of high-quality $\mu \mathrm{c}-\mathrm{Si}: \mathrm{H}$ materials on top..$^{3,21,22}$ The EQE spectra of the two solar cells are compared in Fig. 5. As shown, the plasmonic solar cell exhibits slightly higher EQE than the textured solar cell at short wavelengths from 350 to $600 \mathrm{~nm}$, possibly due to two reasons. First, the solar cells deposited on the plasmonic BR have much smoother top surface than cells on the highly textured BR, which can improve the i/p interface and thus enhance the carriers collection at those short wavelengths. Second, the thickness of ITO in plasmonic solar cell is smaller than the textured solar cells, resulting in lower surface reflection and thus higher EQE. In the wavelength range from 700 to $1100 \mathrm{~nm}$, the EQE of the plasmonic solar cell is slightly lower than the textured solar cell. For the textured $\mathrm{BR}$, the incident light is almost completely scattered as demonstrated by the negligible interference in the EQE curve. However, for the plasmonic BR the incident light is not completely scattered as indicated by the haze curve in Fig. 2(b), which results in the stronger interference and slightly lower EQE than the textured BR. Further increase of the surface coverage of Ag NPs would lead to higher haze value and higher EQE. Overall, the plasmonic BR results in a high photocurrent of $26.3 \mathrm{~mA} / \mathrm{cm}^{2}$ which is comparable to the textured BR $\left(26.7 \mathrm{~mA} / \mathrm{cm}^{2}\right)$. The photocurrent of $26.3 \mathrm{~mA} / \mathrm{cm}^{2}$ is considerably higher than the previous works on plasmonic light trapipng, ${ }^{11-14}$ thanks to the low parasitic absorption and broad angular scattering.

To illustrate the effects of plasmonic BR on the electrical performance of the $\mu \mathrm{c}-\mathrm{Si}: \mathrm{H}$ solar cells, the photovoltaic

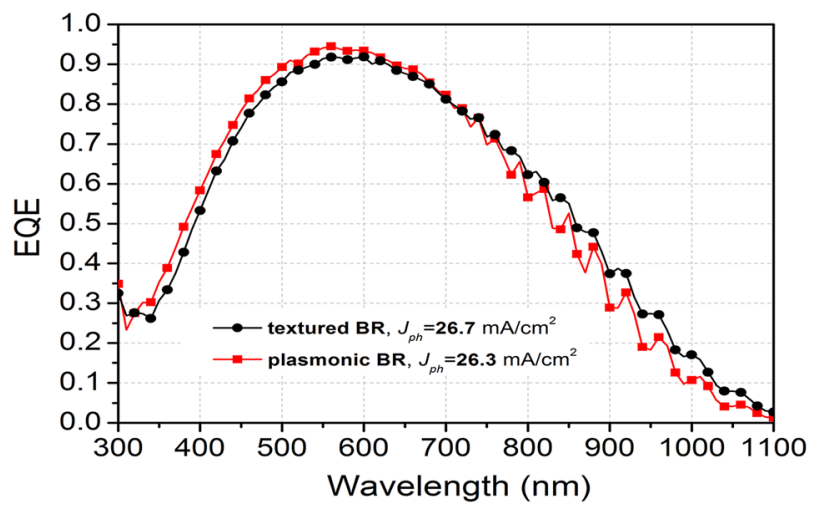

FIG. 5. EQE spectra of solar cells deposited at United Solar on the plasmonic BR and on the state-of-the-art textured Ag/AZO BR. 
TABLE I. Photovoltaic characteristics of solar cells deposited on different BRs at $T U$ Delft and United Solar.

\begin{tabular}{lcccccc}
\hline \hline Devices & BRs & n-layer & $V_{o c}[\mathrm{~V}]$ & $F F$ & $J_{p h}\left[\mathrm{~mA} / \mathrm{cm}^{2}\right]$ & $\eta[\%]$ \\
\hline TU Delft & Flat & $\mu \mathrm{c}-\mathrm{SiO}_{x}: \mathrm{H}$ & 0.479 & 0.663 & 21.0 & 6.3 \\
& Plasmonic & $\mu \mathrm{c}-\mathrm{SiO}_{x}: \mathrm{H}$ & 0.485 & 0.662 & 25.5 & 7.8 \\
\multirow{4}{*}{ United Solar } & Textured & $\mathrm{a}-\mathrm{Si}: \mathrm{H}$ & 0.493 & 0.694 & 26.7 & 9.0 \\
& Plasmonic & $\mathrm{a}-\mathrm{Si}: \mathrm{H}$ & 0.498 & 0.575 & 26.3 & 7.3 \\
\hline \hline
\end{tabular}

parameters are summarized in Table I. For solar cells deposited at TU Delft or United Solar, the $V_{o c}$ of plasmonic solar cells is almost the same as the flat solar cells or the textured solar cells, respectively. The effect of plasmonic BR on the $F F$, however, is different between solar cells deposited at $T U$ Delft and United Solar. For devices deposited at United Solar where hydrogenated amorphous silicon (a-Si:H) n-layer was used, the $F F$ of the plasmonic solar cells $(0.575)$ is lower than that of textured solar cells (0.694). Such a deterioration of $F F$ was also commonly observed in other reports. ${ }^{10-14}$ Although the top surface of the Ag NPs is flattened, the edges of the Ag NPs are still relatively steep. The sharp valleys around the Ag NPs can create cracks (porous defective material) near the $n / i$ interface and inside the intrinsic layer. ${ }^{23}$ Such cracks act as shunting paths and reduce the $F F$, making the plasmonic cell efficiency (7.3\%) much lower than the efficiency of textured solar cells $(9.0 \%)$. Therefore, suppressing the formation of cracks inside the $\mu \mathrm{c}-\mathrm{Si}: \mathrm{H}$ intrinsic layer or preventing the deterioration of $F F$ by proper interface treatment is a key point to achieve high-efficiency solar cells deposited on the plasmonic $\mathrm{BR}$. One possible route is to deposit a thicker $\mathrm{ZnO}: \mathrm{Al}$ layer on top of the Ag NPs and then polish the surface to be flat, as demonstrated by other groups. ${ }^{24,25}$ Another alternative method is to use a $\mu \mathrm{c}-\mathrm{SiO}_{x}: \mathrm{H}$ n-layer which enables $F F$ and $V_{o c}$ more robust to the cracks than the conventional a$\mathrm{Si}: \mathrm{H}$ or $\mu \mathrm{c}-\mathrm{Si}: \mathrm{H}$ doped layers. ${ }^{26,27}$ As demonstrated, the deterioration of $F F$ is not observed for the solar cells deposited at $T U$ Delft which deploy a $\mu \mathrm{c}-\mathrm{SiO}_{x}: \mathrm{H}$ n-layer. There are two possible reasons why the $F F$ of the plasmonic solar cell with a $\mu \mathrm{c}-\mathrm{SiO}_{x}: \mathrm{H}$ n-layer is not degraded. First, the $\mu \mathrm{c}-\mathrm{SiO}_{x}: \mathrm{H}$ layer can quench the shunting paths created by the cracks near the $\mathrm{n} / \mathrm{i}$ interface or inside the i-layer. Second, the mixed-phase nature of $\mu \mathrm{c}-\mathrm{SiO}_{x}: \mathrm{H}$ can act as a barrier to the in-diffusion of contamination atoms from the underlying layer into the $\mu \mathrm{c}-\mathrm{Si}: \mathrm{H}$ intrinsic layer.

In conclusion, the photocurrent of $\mu \mathrm{c}-\mathrm{Si}: \mathrm{H}$ solar cells can be significantly enhanced by a plasmonic BR due to the efficient scattering of incident light by metal nanoparticles. The light trapping performance is improved using a plasmonic BR with broader angular scattering and lower parasitic absorption loss through tuning the size of the plasmonic nanoparticles. The improved plasmonic BR results in a high photocurrent of $26.3 \mathrm{~mA} / \mathrm{cm}^{2}$ which is comparable to the state-of-the-art textured $\mathrm{Ag} / \mathrm{ZnO} \mathrm{BR}$. One potential drawback of using plasmonic BRs is a deterioration of $F F$. However, we show here that this can be avoided using a $\mu \mathrm{c}-\mathrm{SiO}_{x}: \mathrm{H}$ n-layer instead of the conventional a-Si:H n-layer.

The authors would like to thank K. Jäger and O. Isabella for optical measurements and helpful discussions. Financial support from the Dutch STW-VIDI Grant-10782 of A. Smets is gratefully acknowledged.

${ }^{1}$ A. V. Shah, H. Schade, M. Vanecek, J. Meier, E. Vallat-Sauvain, N. Wyrsch, U. Kroll, C. Droz, and J. Bailat, Prog. Photovoltaics 12, 113 (2004).

${ }^{2}$ M. Berginski, J. Hüpkes, M. Schulte, G. Schöpe, H. Stiebig, B. Rech, and M. Wuttig, J. Appl. Phys. 101, 074903 (2007).

${ }^{3}$ G. Yue, L. Sivec, J. M. Owens, B. Yan, J. Yang, and S. Guha, Appl. Phys. Lett. 95, 263501 (2009).

${ }^{4}$ B. Yan, G. Yue, L. Sivec, J. Yang, S. Guha, and C. Jiang, Appl. Phys. Lett. 99, 113512 (2011).

${ }^{5}$ M. Boccard, C. Battaglia, S. Hanni, K. Soderstrom, J. Escarre, S. Nicolay, F. Meillaud, M. Despeisse, and C. Ballif, Nano Lett. 12, 1344 (2012).

${ }^{6}$ H. A. Atwater and A. Polman, Nature Mater. 9, 205 (2010).

${ }^{7}$ T. L. Temple and D. M. Bagnall, "Broadband scattering of the solar spectrum by spherical metal nanoparticles," Prog. Photovoltaics (2012) (online).

${ }^{8}$ F. J. Beck, S. Mokkapati, and K. R. Catchpole, Prog. Photovoltaics 18, 500 (2010).

${ }^{9}$ H. Tan, R. Santbergen, A. H. M. Smets, and M. Zeman, Nano Lett. 12, 4070 (2012).

${ }^{10}$ Eminian, F. J. Haug, O. Cubero, X. Niquille, and C. Ballif, Prog. Photovoltaics 19, 260, (2011).

${ }^{11}$ Moulin, J. Sukmanowski, M. Schulte, A. Gordijn, F. X. Royer, and H. Stiebig, Thin Solid Films 516, 6813 (2008).

${ }^{12}$ U. W. Paetzold, E. Moulin, D. Michaelis, W. Bottler, C. Wachter, V. Hagemann, M. Meier, R. Carius, and U. Rau, Appl. Phys. Lett. 99, 181105 (2011).

${ }^{13}$ J. Bhattacharya, N. Chakravarty, S. Pattnaik, W. D. Slafer, R. Biswas, and V. L. Dalal, Appl. Phys. Lett. 99, 131114 (2011).

${ }^{14}$ J. Chantana, Y. Q. Yang, Y. Sobajima, C. Sada, A. Matsuda, and H. Okamoto, J. Non-Cryst. Solids 358, 2319 (2012).

${ }^{15}$ H. Tan, R. Santbergen, G. Yang, A. H. M. Smets, and M. Zeman, IEEE J. Photovoltaics 3, 53 (2013).

${ }^{16}$ K. Jäger, O. Isabella, R. van Swaaij, and M. Zeman, Meas. Sci. Technol. 22, 105601 (2011).

${ }^{17}$ C. F. Bohren and D. R. Huffman, Absorption and Scattering of Light by Small Particles (Wiley-VCH, Weinheim, 2004).

${ }^{18}$ C. Battaglia, M. Boccard, F. J. Haug, and C. Ballif, J. Appl. Phys. 112, 094504 (2012).

${ }^{19}$ Y. A. Akimov, W. S. Koh, and K. Ostrikov, Opt. Express 17, 10195 (2009).

${ }^{20}$ F. J. Beck, S. Mokkapati, and K. R. Catchpole, Opt. Express 19, 25230 (2011).

${ }^{21}$ B. Yan, G. Yue, L. Sivec, J. Owens-Mawson, J. Yang, and S. Guha, Sol. Energy Mater. Sol. Cells 104, 13 (2012).

${ }^{22}$ L. Sivec, B. Yan, G. Yue, J. Owens-Mawson, J. Yang, and S. Guha, IEEE J. Photovoltaics 3, 27 (2013).

${ }^{23}$ M. Python, E. Vallat-Sauvain, J. Bailat, D. Domine, L. Fesquet, A. Shah, and C. Ballif, J. Non-Cryst. Solids 354, 2258 (2008).

${ }^{24}$ H. Sai, Y. Kanamori, and M. Kondo, Appl. Phys. Lett. 98, 113502 (2011).

${ }^{25}$ K. Soderstrom, G. Bugnon, F. J. Haug, S. Nicolay, and C. Ballif, Sol. Energy Mater. Sol. Cells 101, 193 (2012).

${ }^{26}$ P. Cuony, M. Marending, D. T. L. Alexander, M. Boccard, G. Bugnon, M. Despeisse, and C. Ballif, Appl. Phys. Lett. 97, 213502 (2010).

${ }^{27}$ G. Bugnon, G. Parascandolo, T. Soderstrom, P. Cuony, M. Despeisse, S. Hanni, J. Holovsky, F. Meillaud, and C. Ballif, Adv. Funct. Mater. 22, 3665 (2012). 